\title{
Solar mixed thermal and photovoltaic installation for an infantile educational-sanitary lodging in Senkata-El Alto (BOLIVIA)
}

\author{
A. Daniel Rey Rey ${ }^{b}$, B. Manuel Alejandro Míguez Ruanovab ${ }^{\mathrm{b}}$ C. Francisco Manuel León Mayo ${ }^{\mathrm{b}}$, Iago \\ Fernandez Otero $^{a}$, Vicente Gandara Villadoniga ${ }^{a}$, A. López Agüera ${ }^{a}$ \\ ${ }^{a}$ Department of Particle Physics \& Galician Institute of High Energy Physics \\ ${ }^{\mathrm{b}}$ Master in Renewable Energies \\ South Campus 15702 Santiago de Compostela (Spain) \\ phone:+34 981 563100, fax:+34 981521091, e-mail: A. daniel.rey.rey@gmail.com; B. pardao15@gmail.com; C. \\ franfreixo@gmail.com.
}

\begin{abstract}
.
The paper describes an international cooperation project for depressed zones. The aim of the project is to supply electricity and hot water in a refuge for around 150 children in El Alto (Bolivia) with solar energy.
\end{abstract}

\section{Key words}

Photovoltaic energy. Thermal energy. International cooperation.

\section{Introduction}

It is a fact that much of the world's population doesn't have access to basic services like electricity or hot water. In this case renewable energies are a real alternative to conventional energies, an also the possibility of overcoming the obstacles of this kind of energies.

The performed project is an actuation on a refuge which gives service to 150 children of the lodging and their familiar environment that approaches 1000 persons. Parallel there has been carried out an occupational workshop of renewable energies for the teen population.

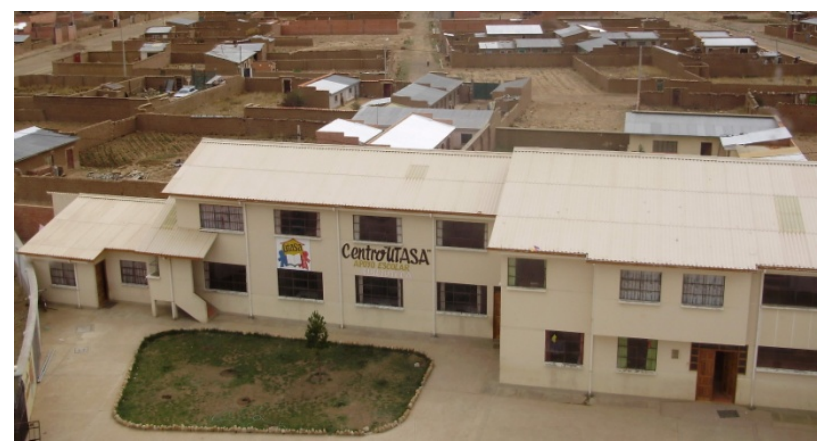

Fig. 1 - The lodging
The refuge is placed in El Alto place (Bolivia). The actuation place is Senkata's neighborhood, placed to 4200 $\mathrm{m}$ of height, to 30 kilometers of La Paz and with one of the climates more end of the planet. This lodging does not have any covers of their basic needs for the daily life. The development of this project is based in achieving a supply of electric power, since the infrastructures of electrical networks in the zone are very precarious and to realize a contribution of warm sanitary water to improve the hygienic - sanitary conditions of the population of the zone. For this motive we have carried out a study of the solar radiation of the zone with the aim to install a photovoltaic and thermal system to correct the above mentioned lacks. Bolivia has a high solar radiation as well as a large number of sunshine hours per day due to climatic and geographical conditions. These factors made of this zone a suitable place for a photovoltaic and thermal installation.

The project has been developed in the frame of international cooperation and includes local government (Dirección Xeral de Cooperación da Xunta de Galizia[1]), university (Universidade de Santiago de Compostela[2]) and diverse companies of the sector. Likewise there constitutes a pioneering experience realized by students of the Master in Renewable Energies[3] as post-graduation project.

\section{Design of the installation}

A) Preliminary study.

For the proper design of the facility is necessary a study of the location. It is also necessary to study climatology and consumption of energy in the building. 


\section{1) Location}

The lodging is situated en El Alto, close to La Paz in Bolivia. Its geographic data are as follows:

TABLE I. - Geographical data

\begin{tabular}{|l|c|}
\hline Longitude & $68^{\circ} 12^{\prime} \mathrm{W}$ \\
\hline Latitude & $16^{\circ} 30^{\prime} \mathrm{S}$ \\
\hline Altitude & $4000 \mathrm{~m}$ \\
\hline
\end{tabular}

\section{2) Climatologically data}

For the development of the project we use as climatologically data "daily global horizontal irradiation" and "temperature". These data were obtained from the NASA[4].

TABLE II. - Climatologically data

\begin{tabular}{|c|c|c|}
\hline MONTH & $\begin{array}{c}\text { Daily global horizontal } \\
\text { irradiation (Kwh/m2) }\end{array}$ & Temperature $\left({ }^{\mathbf{}} \mathbf{C}\right)$ \\
\hline January & 6,2 & 10,5 \\
\hline February & 6,3 & 10,1 \\
\hline March & 6,0 & 9,74 \\
\hline April & 5,8 & 8,61 \\
\hline May & 5,5 & 7,08 \\
\hline June & 5,2 & 5,97 \\
\hline July & 5,3 & 5,72 \\
\hline August & 5,7 & 7,18 \\
\hline September & 6,5 & 8,58 \\
\hline October & 6,8 & 10 \\
\hline November & 7,1 & 10,7 \\
\hline December & 6,8 & 10,7 \\
\hline Annual & 6,1 & \multicolumn{1}{|c|}{} \\
\cline { 1 - 2 } & &
\end{tabular}

\section{3) Consumption of the building.}

For the study of energy consumption of the building is necessary to distinguish between electricity consumption and the consumption of hot water.

TABLE III. - Electric consumption of the building

\begin{tabular}{|l|c|c|c|c|}
\hline Element & $\begin{array}{c}\text { Number of } \\
\text { elements }\end{array}$ & Power (W) & $\begin{array}{c}\text { Daily } \\
\text { use(hours) }\end{array}$ & Wh/day \\
\hline Bulbs & 40 & 18 & 2 & 1440 \\
\hline PC's & 3 & 210 & 6 & 3780 \\
\hline Fridge & 2 & 600 & 6 & 7200 \\
\hline TV DVD & 1 & 75 & 0,15 & 11,25 \\
\hline Heat pump & 1 & 60 & 12 & 720 \\
\hline $\begin{array}{l}\text { Extractor } \\
\text { hood }\end{array}$ & 1 & 200 & 0,2 & 40 \\
\hline Others & 1 & 300 & 1 & 300 \\
\hline Standby & 1 & 2 & 24 & 48 \\
\hline \multicolumn{1}{|c|}{ TOTAL } & & & & $\mathbf{1 3 5 3 9 , 2 5}$ \\
\hline
\end{tabular}

To calculate the consumption of hot water in the building we assumed the use of about 40 showers a day, with about 20 liters per shower.

It is also necessary to estimate a percentage of monthly occupation. In January the building is practically inoperative due to the period of holidays. It is also important the temperature of the water for each month

TABLE IV. - Hot water consumption

\begin{tabular}{|c|c|c|c|}
\hline MONTH & $\begin{array}{c}\text { \% } \\
\text { OCUPATION }\end{array}$ & $\begin{array}{c}\text { MONTHLY } \\
\text { COMSUMPTION } \\
(\mathbf{m} 3)\end{array}$ & $\begin{array}{c}\text { WATER } \\
\text { TEMPERATURE } \\
\left({ }^{\circ} \mathbf{C}\right)\end{array}$ \\
\hline January & 10 & 2 & 10 \\
\hline February & 100 & 22 & 10 \\
\hline March & 100 & 25 & 10 \\
\hline April & 100 & 24 & 6 \\
\hline May & 100 & 25 & 6 \\
\hline June & 100 & 24 & 6 \\
\hline July & 100 & 25 & 6 \\
\hline August & 100 & 25 & 6 \\
\hline September & 100 & 24 & 6 \\
\hline October & 100 & 25 & 10 \\
\hline November & 100 & 24 & 10 \\
\hline December & 75 & 19 & 10 \\
\hline
\end{tabular}

\section{B. Design of installation}

Whatever installation you have got, the first step is to know what inclination is the optimum for the panels. Reading the technical conditions article of IDAE[5], the optimum inclination to be sure that annual needs are supplied, is given by latitude minus $10^{\circ}$, so the chosen inclination will be around $6^{\circ}$.

Now it should be planning both installations separately.

\section{1) Photovoltaic installation.}

To do this design, we will follow a method written in the technical conditions article of IDAE.

Firstly, calculate the lighting factor FI:

$$
\begin{array}{ll}
F I=1-\left[1,2 \cdot 10^{-4} \cdot\left(\beta-\beta_{\text {opt }}\right)^{2}+3,5 \cdot 10^{-5} \alpha^{2}\right] & \text { to } 15^{\circ}<\beta<90^{\circ}(1) \\
F I=1-\left[1,2 \cdot 10^{-4} \cdot\left(\beta-\beta_{\text {opt }}\right)^{2}\right] & \text { to } \beta \leq 15^{\circ}
\end{array}
$$

Where $\beta$ is the real inclination of panel, $\beta_{\text {opt }}$ is the optimum inclination, and $\alpha$ is the azimuth of panel.

Secondly, it should be calculated the shadow factor. To get it, it's necessary a pattern of shadows with a right table. However, there aren't any shadow in the place where the panels will be located. So, by this way the value of the shadow factor is 1 . 
The next step is to get a correction for the level inclination of horizontal irradiation. It is needed the "correction factor by inclination", K. In this case, the inclination has got a negligible number, so $\mathrm{K}$ is equal to 1.

Finally, the irradiation that panels will get is shown by:

$$
G_{d m}(\alpha, \beta)=G_{d m}(0) \cdot K \cdot F I \cdot F S
$$

Where $\mathrm{G}_{\mathrm{dm}}(0)$ is horizontal global irradiation y $\mathrm{G}_{\mathrm{dm}}(\alpha, \beta)$ is corrected global irradiation.

In this table, results are shown:

TABLE IV. - Corrected diary Irradiation.

\begin{tabular}{|c|c|c|c|}
\hline MONTH & \begin{tabular}{|c|} 
DIARY \\
HORIZONTAL \\
IRRADIATION \\
$\left(\mathbf{K w h} / \mathbf{m}^{2}\right)$
\end{tabular} & $\mathbf{K}$ & $\begin{array}{c}\text { DIARY } \\
\text { CORRECTED } \\
\text { INCLINATED } \\
\text { IRRADIATION } \\
\left(\mathrm{Kwh} / \mathbf{m}^{2}\right)\end{array}$ \\
\hline January & 6,2 & 0,93 & 5,79 \\
\hline February & 6,3 & 0,97 & 6,05 \\
\hline March & 6,0 & 1,02 & 6,10 \\
\hline April & 5,8 & 1,1 & 6,33 \\
\hline May & 5,5 & 1,18 & 6,53 \\
\hline June & 5,2 & 1,23 & 6,39 \\
\hline July & 5,3 & 1,21 & 6,37 \\
\hline August & 5,7 & 1,14 & 6,48 \\
\hline September & 6,5 & 1,06 & 6,86 \\
\hline October & 6,8 & 0,99 & 6,72 \\
\hline November & 7,1 & 0,93 & 6,59 \\
\hline December & 6,8 & 0,91 & 6,16 \\
\hline ANUAL & 6,09 & & 6,36 \\
\hline
\end{tabular}

The next math expression allows calculate the minimum power to install:

$$
P_{m p}=\frac{E_{D} \cdot G_{C E M}}{G_{d m}(\alpha, \beta) \cdot P R}
$$

Where:

$$
\mathrm{G}_{\mathrm{CEM}}=1 \mathrm{~kW} / \mathrm{m}^{2}
$$

$\mathrm{E}_{\mathrm{D}}$ in $\mathrm{kWh} /$ day

PR is performance ratio, which bear in mind energy loss that happen in installation owing to different systems. So its value is $\mathrm{PR} \approx 0,7$ for a isolated system with electronic inverter; and $\mathrm{PR} \approx 0,6$ for isolated system with electronic inverter+battery (our case).

Having all this, our minimum power to install will be $3,54 \mathrm{~kW}$.

We chose panels with a peak power of $175 \mathrm{Wp}$. By this way, we should install 20 panels and this implies 3500 Wp.
To make the sizing of accumulation system we have to consider the place has got a high radiation levels that means 1,5 days of autonomy should be enough. We use the following expression to get the size of accumulation system:

$$
C=\frac{A \cdot L_{D}}{P D_{\max } \bullet \eta_{i n v} \bullet \eta_{r b}}
$$

Where:

$-\mathrm{C}$ : nominal capacity of accumulator in Ah -A: autonomy of system in days, 1,5 days. $-\mathrm{PD}_{\max }$ : Maximum depth of discharge, 0,7 . $-\mu_{\text {inv }}$ : yield of electronic inverter 0,85 .

$-\mu_{\mathrm{rb}}$ : energy yield of system 0,81 . Accumalator+regulator

$-\mathrm{L}_{\mathrm{D}}$ : daily average requirement of load in $\mathrm{Ah}$, 282,07Ah.

We need a capacity of $877 \mathrm{Ah}$. We decided to make an oversizing of accumulation system to make up for the loss of load by time. Chosen batteries have got a capacity of $150 \mathrm{Ah}$ for a working voltage of $12 \mathrm{~V}$. The used matrix was this:

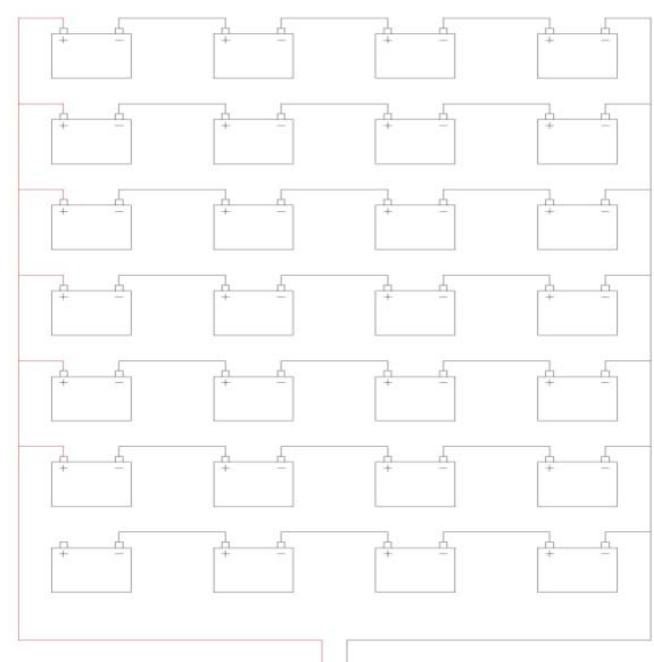

Fig. 2. Accumulation Matrix.

So, our accumulation system is characterized by $1050 \mathrm{Ah}$ and $48 \mathrm{~V}$.

Following it is showed the used diagram of installation: 


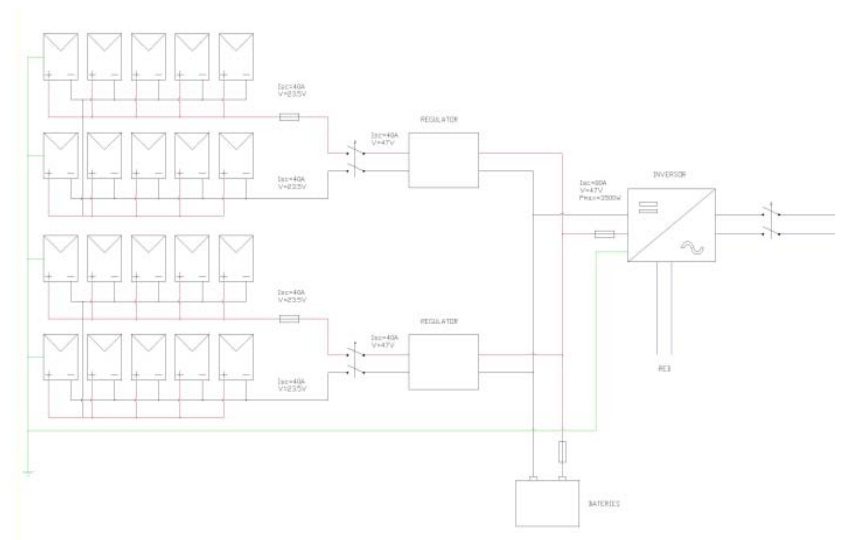

Fig. 3. Photovoltaic diagram.

As we can see in the diagram, we use two regulators and only one electric inverter.

To make the sizing of the wiring we use the next expression:

$$
S=\frac{\rho_{C u} \cdot 200 \cdot L \cdot P}{\%_{e} \cdot V^{2}}
$$

Where:

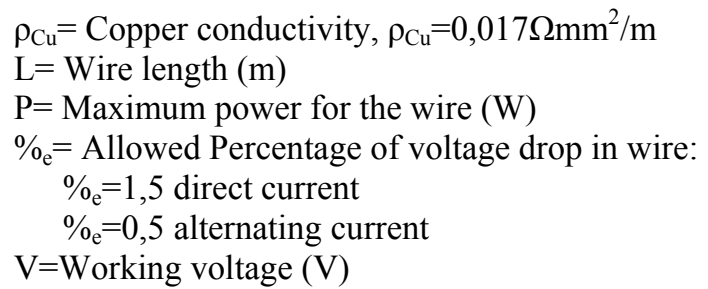

\section{2) Thermal Installation.}

The first step in the design of the installation is the sizing of thermal collection system. To do this we use the fChart method, which is based on the calculation of the number $f$, which is the ratio of useful energy captured and the heating load each month, and can be calculated as follows:

$$
f=1,029 D_{1}-0,065 D_{2}-0,245 D_{1}^{2}+0,0018 D_{2}^{2}+0,0215 D_{1}^{3}
$$

For this, we must follow these steps:

-Heating load study for warm water. This gives us the quantity of heat necessary each month:

$$
Q_{a}=C_{e} C N\left(t_{a c}-t_{r}\right)
$$

Where:

$\mathrm{Q}_{\mathrm{a}}=$ Monthly heating load for warm water ( $\mathrm{J} /$ month)

$\mathrm{C}_{\mathrm{e}}=$ Specific heat. For water $4187 \mathrm{~J} /\left(\mathrm{kg}^{\circ} \mathrm{C}\right)$

$\mathrm{C}=$ Daily hot water consumption (1/day)

$\mathrm{t}_{\mathrm{ac}}=$ Temperature of hot water accumulation $\left({ }^{\circ} \mathrm{C}\right)$ $\mathrm{t}_{\mathrm{r}}=$ Water temperature of the net $\left({ }^{\circ} \mathrm{C}\right)$

$\mathrm{N}=$ Number of days per month

-Calculation of the parameter D1. This parameter indicates the relationship between energy absorbed by the panel and the total monthly load:

$\mathrm{D}_{1}=$ Absorbed energy by the panel/Monthly thermal load

The energy absorbed by the panel is given by:

$$
E_{a}=S_{C} F_{r}^{\prime}(\tau \alpha) R_{1} N
$$

Where:

$\mathrm{S}_{\mathrm{C}}=$ Capture surface $\left(\mathrm{m}^{2}\right)$

$\mathrm{R}_{1}=$ Monthly average daily radiation incident on the surface of catchment area per unit of area $\left(\mathrm{kJ} / \mathrm{m}^{2}\right)$

$\mathrm{N}=$ Number of days per month

$\mathrm{F}_{\mathrm{r}}^{\prime}(\tau \alpha)=$ Adimensional factor given by:

$$
F_{r}^{\prime}(\tau \alpha)=F_{r}(\tau \alpha)_{n}\left[(\tau \alpha) /(\tau \alpha)_{n}\right]\left(F_{r}^{\prime} / F_{r}\right)
$$

Where:

$$
\begin{aligned}
& \mathrm{F}_{\mathrm{r}}(\tau \alpha)_{\mathrm{n}}=\text { Optical efficiency factor of the panel } \\
& \begin{aligned}
(\tau \alpha) /(\tau \alpha)_{\mathrm{n}}= & \text { Angle of incidence modificator. It } \\
& \text { usually takes as a constant: } 0,96 \\
& \text { (simple transparent surface) o } 0,94 \\
& \text { (double transparent surface). }
\end{aligned} \\
& \mathrm{F}_{\mathrm{r}}^{\prime} / \mathrm{F}_{\mathrm{r}}=\text { Correction factor of the entire panel-heat } \\
& \text { exchanger. It is advisable a value } 0,95 .
\end{aligned}
$$

-Calculation of the parameter $\mathrm{D}_{2}$. This parameter indicates the relationship between the loss of energy in the panel and the monthly load.

$\mathrm{D}_{2}=$ Energy lost by the collector / monthly heat load

Energy lost by the collector is calculated as follows:

$$
E_{p}=S_{c} \cdot F_{r}^{\prime} U_{L} \bullet\left(100-t_{a}\right) \bullet \Delta t \cdot K_{1} \bullet K_{2}
$$

Where:

$\mathrm{S}_{\mathrm{c}}=$ Collector surface.

$\mathrm{F}^{\prime}{ }_{\mathrm{r}} \mathrm{U}_{\mathrm{L}}=\mathrm{F}_{\mathrm{r}} \mathrm{U}_{\mathrm{L}}\left(\mathrm{F}_{\mathrm{r}} / \mathrm{F}_{\mathrm{r}}\right)$

Where:

$\mathrm{F}_{\mathrm{r}} \mathrm{U}_{\mathrm{L}}=$ Overall loss coefficient of the collector. $\mathrm{t}_{\mathrm{a}}=$ Monthly average temperature of the environment $\Delta \mathrm{t}=$ Period of time considered in seconds.

$\mathrm{K}_{1}=$ Correction factor for storage, is calculated as:

$$
\begin{aligned}
& K_{1}=\left[\mathrm{kg} \text { accumulation } /\left(75 S_{c}\right)\right]^{-0,25} \\
& 37,5<(\mathrm{kg} \text { accumulation }) /\left(\mathrm{m}^{2} \text { collector }\right)<300
\end{aligned}
$$


$\mathrm{K}_{2}=$ Correction factor, it relates minimum temperature of hot water, net water and monthly average of the environment as follows:

$$
K_{2}=11,6+1,18 t_{a c}+3,86 t_{r}-2,32 t_{a} /\left(100-t_{a}\right)
$$

Where:

$$
\begin{aligned}
& t_{a c}=\text { Minimum temperature of hot water } \\
& t_{r}=\text { Temperature of net water } \\
& t_{a}=\text { Monthly average temperature of environment }
\end{aligned}
$$

With this method, we estimate the number $f$ for each month. We will vary the number of panels to find the minimum number of panels that gives us greater annual coverage. We must consider, for security reasons, do not reach $f \geq 1$ in more than three consecutive months. For our installation, this is achieved using 6 collectors and a volume of 1000 liters of accumulation.

TABLE VI. - Factor $f$

\begin{tabular}{|c|c|}
\hline MONTH & f \\
\hline January & 1,0000 \\
February & 0,8594 \\
March & 0,8736 \\
April & 0,8631 \\
May & 0,8828 \\
June & 0,8636 \\
July & 0,8638 \\
August & 0,8779 \\
September & 0,9157 \\
October & 0,9378 \\
November & 0,9235 \\
December & 1,0000 \\
\hline
\end{tabular}

The chosen scheme is as follows:

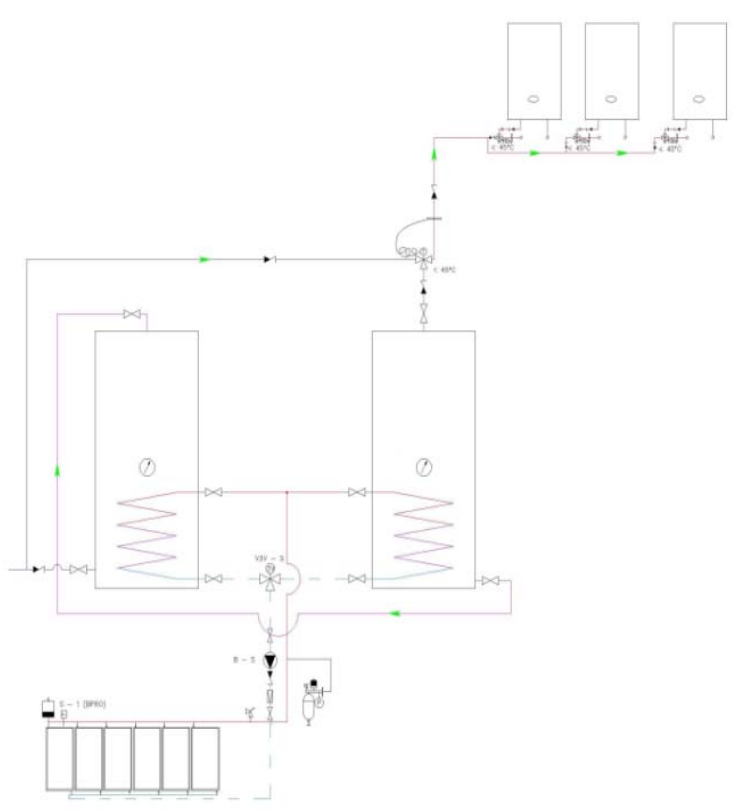

Fig. 4. Thermal Scheme.
For dimensioning the size of the pipe, we assumed a length for the primary installation of 24 meters. Since the loss of load must be less than $40 \mathrm{~mm}$ ca per meter of pipe, through appropriate abacus, we get a diameter of $22 \mathrm{~mm}$.

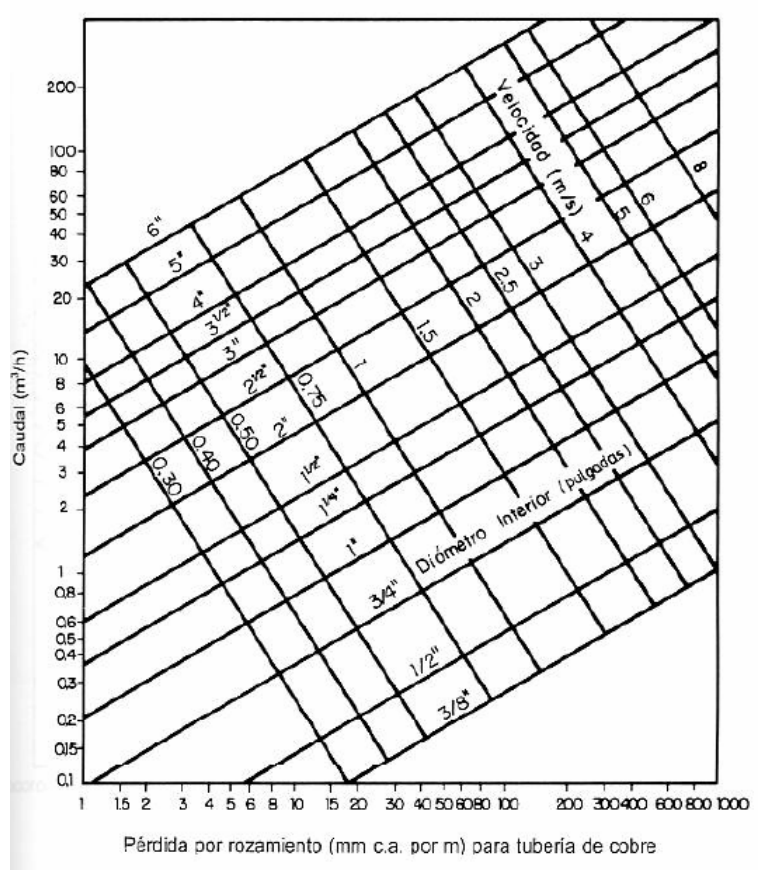

Fig. 5. Abacus for the calculation of the load loss for cooper pipe

We must also install an appropriate expansion tank. To do this we use the following calculations:

$$
V_{t}=V \cdot C_{e} \cdot C_{p}
$$

Where:

$\mathrm{V}_{\mathrm{t}}=$ Total volume of expansion tank (1)

$\mathrm{V}=$ Total volume of working fluid in the circuit (1)

$\mathrm{C}_{\mathrm{e}}=$ Expansion coefficient of the fluid. In a mixing water+antifreeze, its value is $\mathrm{C}_{\mathrm{e}}=0,07$

$\mathrm{C}_{\mathrm{p}}=$ Pressure coefficient. It is given by:

$$
C_{p}=\frac{P_{\max }+1}{P_{\max }-P_{\min }}
$$

Where:

$\mathrm{P}_{\max }=$ Maximum pressure of operation admissible in the expansion tank (bar). It is calculated as follows:

$$
P_{\max }=P_{V S}-0,3 b a r
$$

$\mathrm{P}_{\min }=$ Minimum pressure of the expansion (bar).

$$
P_{\min }=0,5 b a r+P_{e s t}
$$


Where:

$\mathrm{P}_{\text {est }}=$ Static Pressure.

$$
P_{\text {est }}=h(m) \bullet 0,1 \mathrm{bar} / \mathrm{m}
$$

Finally, we decided to oversize the expansion tank for security and because in December and January (summer months) the center has a low occupancy, and this can produce an overheating of the installation. In figure 4 the expected results are shown.

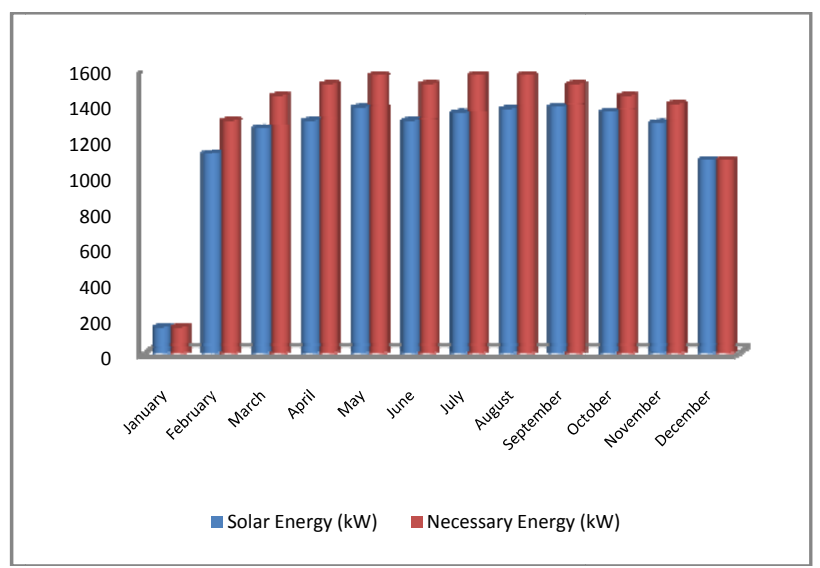

Fig. 6. Expected results in energetic saving.

\section{Conclusion}

The presented project allowed to supply a center for disadvantaged children with warm water and led to a reduction in electricity consumption. The cost savings that this involves, will allow the center an improvement in the budget of the institution in which teaching materials are concerned.

This project constitutes an example that how renewable energies are an alternative to conventional energy in areas to which these can hardly arrive to. While the price of such facilities may be too high for these areas, international collaborative projects involve a good way to overcome these obstacles.

The project has been executed by the authors as final Project for the Master in Renewable Energies and will be protocolized for futures actuations.

\section{Acknowledgements:}

Financial support of the Dirección Xeral de Cooperación Exterior da Xunta de Galicia and Universidade de Santiago de Compostela.

Logistic support of the ADSIS-UTAXAMA people and in particular to Mari Luz Arruti Sarasola.

Technical support from the Photovoltaic Application Group of USC and Carlos Fernandez from NEPNERXIA.

\section{References}

[1] Xunta de Galicia: http://www.xunta.es

[2] Universidade de Santiago de Compostela: http://www.usc.es

[3] Master en Energias Renovables y Sostenibilidad Energetica: http://www.usc.es/posgrao/merese07

[4] NASA: http://eosweb.larc.nasa.gov

[5] Instituto para la diversificación y ahorro de Energía IDAE. http:/ www.idae.es 